\title{
Effect of Nutrients, Dietary Supplements and Vitamins on Cognition: a Systematic Review and Meta-Analysis of Randomized Controlled Trials
}

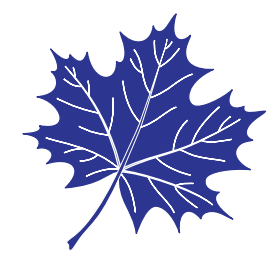

\author{
Scott C. Forbes, $\mathrm{PhD}^{1}$, Jayna M. Holroyd-Leduc, MD ${ }^{4,5}$, Marc J. Poulin PhD, DPhil ${ }^{1,2}$, David B. Hogan MD $2,3,4,5$ \\ ${ }^{1}$ Department of Physiology and Pharmacology, Faculty of Medicine, University of Calgary, Calgary, AB; ${ }^{2}$ Hotchkiss Brain \\ Institute, Faculty of Medicine, University of Calgary, Calgary, AB; ${ }^{3}$ Brenda Stafford Foundation Chair in Geriatric Medicine, \\ Faculty of Medicine, University of Calgary, Calgary, AB; ${ }^{4}$ Departments of Medicine, Clinical Neurosciences and Community \\ Health Sciences, Faculty of Medicine, University of Calgary, Calgary, AB; ${ }^{5}$ Alberta Seniors Health Strategic Clinical \\ Network, Alberta Health Services, Calgary, AB
}

DOI:http://dx.doi.org/10.5770/cgj.18.189

\begin{abstract}
Background

Observational studies have suggested that various nutrients, dietary supplements, and vitamins may delay the onset of age-associated cognitive decline and dementia. We systematically reviewed recent randomized controlled trials investigating the effect of nutritional interventions on cognitive performance in older non-demented adults.
\end{abstract}

\section{Methods}

We searched MEDLINE, CINAHL, Embase, and the Cochrane Library for articles published between 2003 and 2013. We included randomized trials of $\geq 3$ months' duration that examined the cognitive effects of a nutritional intervention in non-demented adults $>40$ years of age. Meta-analyses were done when sufficient trials were available.

\section{Results}

Twenty-four trials met inclusion criteria (six omega-3 fatty acids, seven B vitamins, three vitamin E, eight other interventions). In the meta-analyses, omega-3 fatty acids showed no significant effect on Mini-Mental State Examination (MMSE) scores (four trials, mean difference $0.06,95 \%$ CI $-0.08-0.19$ ) or digit span forward (three trials, mean difference $-0.02,95 \%$ CI $-0.30-0.25)$, while B vitamins showed no significant effect on MMSE scores (three trials, mean difference 0.02, $95 \%$ CI $-0.22-0.25)$. None of the vitamin E studies reported significant effects on cognitive outcomes. Among the other nutritional interventions, statistically significant differences between the intervention and control groups on at least one cognitive domain were found in single studies of green tea extract, Concord grape juice, chromium picolinate, betacarotene, two different combinations of multiple vitamins, and a dietary approach developed for the control of hypertension.

\section{Conclusions}

Omega-3 fatty acids, B vitamins, and vitamin E supplementation did not affect cognition in non-demented middle-aged and older adults. Other nutritional interventions require further evaluation before their use can be advocated for the prevention of age-associated cognitive decline and dementia.

Key words: nutrition, micro-nutrients, macro-nutrients, dementia

\section{INTRODUCTION}

By 2050, the number of individuals with dementia worldwide is projected to reach 135 million. ${ }^{(1)}$ Dementia, a devastating condition, adversely affects the cognitive abilities, independence, and quality of life of those affected and leads to health costs equivalent to those of heart disease and cancer. ${ }^{(2)}$ In 2012, the World Health Organization declared dementia a public health priority. ${ }^{(3)}$

The mechanisms underlying the development of ageassociated cognitive decline and dementia are felt to be operant $10-15$ years or more before the development of clinical symptoms. ${ }^{(4,5)}$ Recent reports suggest that there is a decline in the age-specific prevalence of dementia, ${ }^{(6-8)}$ providing indirect evidence of potentially modifiable risk factors. ${ }^{(5)}$ Effective strategies that can ameliorate the anticipated 
dramatic growth in the number of individuals affected by dementia brought on by population aging are needed..$^{(3,5)}$ In the absence of curative treatment, ${ }^{(9)}$ preventing or postponing the onset of dementia is of critical importance. ${ }^{(5)}$ A five-year delay in the development of Alzheimer's disease (the most common neurodegenerative cause of late-life dementia) would reduce its prevalence by $50 \%$. $^{(10)}$

While to date no interventions have been shown to conclusively decrease the risk of age-associated cognitive decline or the development of Alzheimer's disease, ${ }^{(9)}$ there is a large body of evidence from observational studies suggesting that vitamins, nutrients, and dietary supplements (e.g., omega-3 fatty acids, ${ }^{(11,12)}$ folic acid, ${ }^{(13)}$ vitamins B6, ${ }^{(13)}$ $\mathrm{B} 12,{ }^{(13)} \mathrm{C},{ }^{(14,15)} \mathrm{D},{ }^{(16)}$ and $\mathrm{E}^{(14,15)}$ may delay the onset of ageassociated cognitive decline and various forms of dementia including Alzheimer's disease. ${ }^{(17,18)}$ A variety of mechanisms including correction of metabolic derangements or dietary deficiencies have been proposed by which they may affect cognitive health. ${ }^{(19)}$

The purpose of this systematic review is to summarize the findings of recent randomized controlled trials (RCTs) investigating the cognitive impact of nutritional interventions (e.g., nutrients [including macro-nutrients, vitamins, or minerals], diet, dietary supplement, fortified food, or medical food) of three months or longer in middle-aged and older ( $>$ 40 years) non-demented adults. We performed meta-analyses of the effects where possible.

\section{METHODS}

The approach outlined in the Cochrane Handbook for Systematic Reviews of Interventions ${ }^{(20)}$ was followed and the reporting was done in accordance with PRISMA (Preferred Reporting Items for Systematic Reviews and Meta-Analyses). ${ }^{(21)}$

\section{Data Sources and Search Strategy}

Literature searches were performed in June 2013 on MEDLINE, Embase, CINAHL, and the Cochrane Database of Systematic Reviews. For the MEDLINE search, the Medical Subject headings (MeSH) terms (exploded) Delirium, Dementia, Amnestic, and Cognitive Disorders with the subheading "prevention and control" were combined with the terms Nutrition Assessment, Nutrition Therapy, Diet, Micronutrients and Food, plus Nutrition as a keyword. Delirium, dementia, and other related terms were searched with the diet therapy subheading as a separate set. A supporting keyword search was also done: (cognition disorder* or Alzheimer* or mild cognitive decline) AND (food* or diet* or nutrition* or apolipoprotein* or lipoprotein* or micronutrient* or mineral*). Searches were limited to meta-analyses, systematic reviews, or RCTs performed on middle-aged and/ or older human study populations and published between 2003 and June 2013. Other systematic reviews surveyed the literature prior to 2006. ${ }^{(22-24)}$ Our systematic review was intended to update this prior work. We wanted to focus on those nutritional interventions attracting the greatest current interest. A concern we had in including older studies was the change that that has occurred in typical food intake over the last $20+$ years $^{(25)}$ as there is evidence that baseline dietary intake may impact on the effect that dietary supplements have on cognitive function. The other databases were searched by similar strategies using terms from their specific thesauri. The search was not limited to articles written in any specific language. The full search strategy is attached in Appendix 1. Other articles included in our systematic review were either known by the authors or identified by manually searching the bibliographies of retrieved articles.

\section{Study Selection}

Two of the authors independently screened the titles and abstracts of each of the articles identified in the search for possible inclusion in our systematic review. Articles were selected for full-text review if they met the following criteria: (i) RCT where participants were allocated to either a dietary intervention (e.g., nutrient [including macro-nutrients, vitamins, or minerals], diet, dietary supplement, fortified food, or medical food) or a control arm; (ii) all participants were 40 years of age or older and judged to have normal cognition or mild cognitive impairment (note: if it was not explicitly noted that all cases of diagnosed or suspected dementia were excluded, a study was not selected for full-text review); (iii) intervention duration three or more months (to exclude studies that dealt with the acute effects of nutritional interventions); and, (iv) included cognition as an outcome measure. Discrepancies were resolved either by consensus or the involvement of a third author if necessary.

Full-text articles were reviewed independently by two of the authors for their eligibility of inclusion in the systematic review. Study quality, based on the procedures used for randomization, allocation concealment and blinding, ${ }^{(20)}$ and excluding persons with an underlying condition that could affect cognition, was considered during the study selection process.

\section{Data Extraction}

Full-text articles selected for inclusion had the following information extracted: authors, country where the study was done, date of publication, information on specific inclusion and exclusion criteria, sample size, proportion of total sample that was female, proportion of total sample completing the study, mean age, other characteristics of the study population, nutritional intervention used (including information on dose and frequency of a supplement), duration of study, intervention and control adherence, outcome measures, and results. We focused on examining the outcome measure(s) results as reported for the entire group. As mean (standard deviation [SD]) change in the cognitive 
outcome(s) from baseline was frequently not reported, we noted the final mean value, SD, and number of participants in each group. If a trial had two or more intervention arms, combining their data was considered if the arms were judged similar (e.g., they used the same nutritional intervention except for dosage) ${ }^{(20)}$ and the same control group was utilized. This was done with one study ${ }^{(26)}$ where we pooled two intervention arms (moderate and higher dosages of the same nutritional intervention).

Two authors extracted the data independently with any disagreements resolved by consensus or the involvement of a third author if necessary.

\section{Assessment of the Risk for Bias in Included Studies}

Two of the authors independently assessed and rated the trials for their risk of bias based on criteria derived from the Cochrane Handbook for Systematic Reviews of Interventions. ${ }^{(20)}$ The methods used for randomization and blinding were examined. A low risk of bias was considered present when the approach taken was deemed adequate for both randomization and blinding, moderate if the approach taken was either unclear or only partially met the pre-determined criteria for adequacy, and high risk when these pre-determined criteria were not met. Disagreements were resolved by consensus or the involvement of a third author if necessary.

\section{Data Analysis}

A meta-analysis was done if three or more studies examined the same intervention with the same outcome measure. We did not encounter any situations where two studies examined the same intervention with the same outcome measure where a meta-analysis could have been performed. A fixed effect model was used. A summary measure of the mean difference with a $95 \%$ confidence interval (CI) was calculated. Statistical analysis for heterogeneity was assessed using chisquare test for heterogeneity and the $I^{2}$ statistic to quantify total variation across studies attributable to heterogeneity. Meta-analysis results are presented as forest plots. Funnel plots of the meta-analyses were visually inspected to look for evidence of publication bias, but statistical testing was not done because of the small number $(<10 /$ meta-analysis) of included studies. Statistical analyses were performed using the software program Review Manager (Review Manager 5.2; The Nordic Cochrane Centre, Copenhagen, Denmark).

\section{RESULTS}

\section{Study Characteristics}

Two hundred and sixty citations, excluding duplicate entries, were identified as potentially relevant. After the initial screening of titles and abstracts, 49 full-text articles were retrieved for detailed review (Figure 1). Twenty-four articles met our inclusion criteria for the systematic review (Appendix 2 lists retrieved full-text articles excluded from the systematic review). While most studies had multiple cognitive outcomes, ten had a single or designated primary outcome.

Six trials examined the effects of omega- 3 fatty acid supplementation (Table 1). Among these studies, there was a large amount of heterogeneity with regards to the dosage used (400 $\mathrm{mg}$ to $2200 \mathrm{mg}$ ) and duration of the intervention (6 months to 3.3 years). Three found a modest beneficial effect on memory and/or executive functioning, ${ }^{(27-29)}$ while the other three reported none. ${ }^{(26,30,31)}$

Meta-analyses of omega-3 fatty acid studies were performed for the outcomes of MMSE scores and digit span forward results (Figure 2(a) and (b)). The summary mean difference for MMSE scores was non-significant at $0.06(95 \%$ CI -0.08 to $0.19, p=.40$ ), and the summary mean difference for digit span forward was non-significant at - 0.02 (95\% CI -0.30 to $0.25, p=.87$ ).

Seven trials investigated the effects of various combinations of folate, B6 and/or B12 vitamins (Table 2). There was substantial heterogeneity between trials with regards to dose, intervention duration (12 weeks to 6.6 years), participant health status (suffering from or at risk for cardiovascular disease to healthy community-dwelling individuals), and cognitive outcomes assessed. Inconsistent results were seen with some studies reporting modest benefits in at least one cognitive domain, ${ }^{(32-35)}$ while others found no effect. ${ }^{(36-38)}$

Three studies were pooled to examine the impact on MMSE scores of folate combined with vitamins B6 and/or B12 (Figure 3). The summary mean difference for MMSE scores was non-significant at $0.02(95 \% \mathrm{CI}-0.22$ to $0.25, p=.90)$.

Three trials investigated vitamin E supplementation (Table 3). They were relatively large (769 to 6377 participants) (39-41) and of long duration (3 to 9.6 years). One trial was limited to participants with amnestic mild cognitive impairment. ${ }^{(39)}$ No statistically significant effect on any of the cognitive outcomes examined was found. ${ }^{(39-41)}$

Among the other nutritional interventions examined (Table 4), statistically significant differences between the intervention and control groups on at least one cognitive domain were found for green tea extract, ${ }^{(42)}$ Concord grape juice, ${ }^{(43)}$ chromium picolinate, ${ }^{(44)}$ beta-carotene, ${ }^{(45)}$ two different combination therapies including multiple vitamins, ${ }^{(46,47)}$ and a dietary approach developed for the control of hypertension. (48) No beneficial effects were found for calcium carbonate combined with vitamin D3. ${ }^{(49)}$

A variety of approaches were used to assess adherence to the nutritional interventions including counting capsules, ${ }^{(26,27,31,32,35,37,42-44,47)}$ weighing pills, ${ }^{(49)}$ questionnaires, ${ }^{(33,45)}$ diaries, ${ }^{(32,46)}$ interviews, ${ }^{(34,49)}$ and/or blood analyses. ${ }^{(28,30,37,38)}$ All studies reporting on adherence described it as good or better (e.g., consumption of $2 / 3+$ of all capsules) with the intervention. ${ }^{(30,31,33,35,37,40,41,49)}$ Two studies did not attempt to assess adherence. ${ }^{(29,48)}$ 


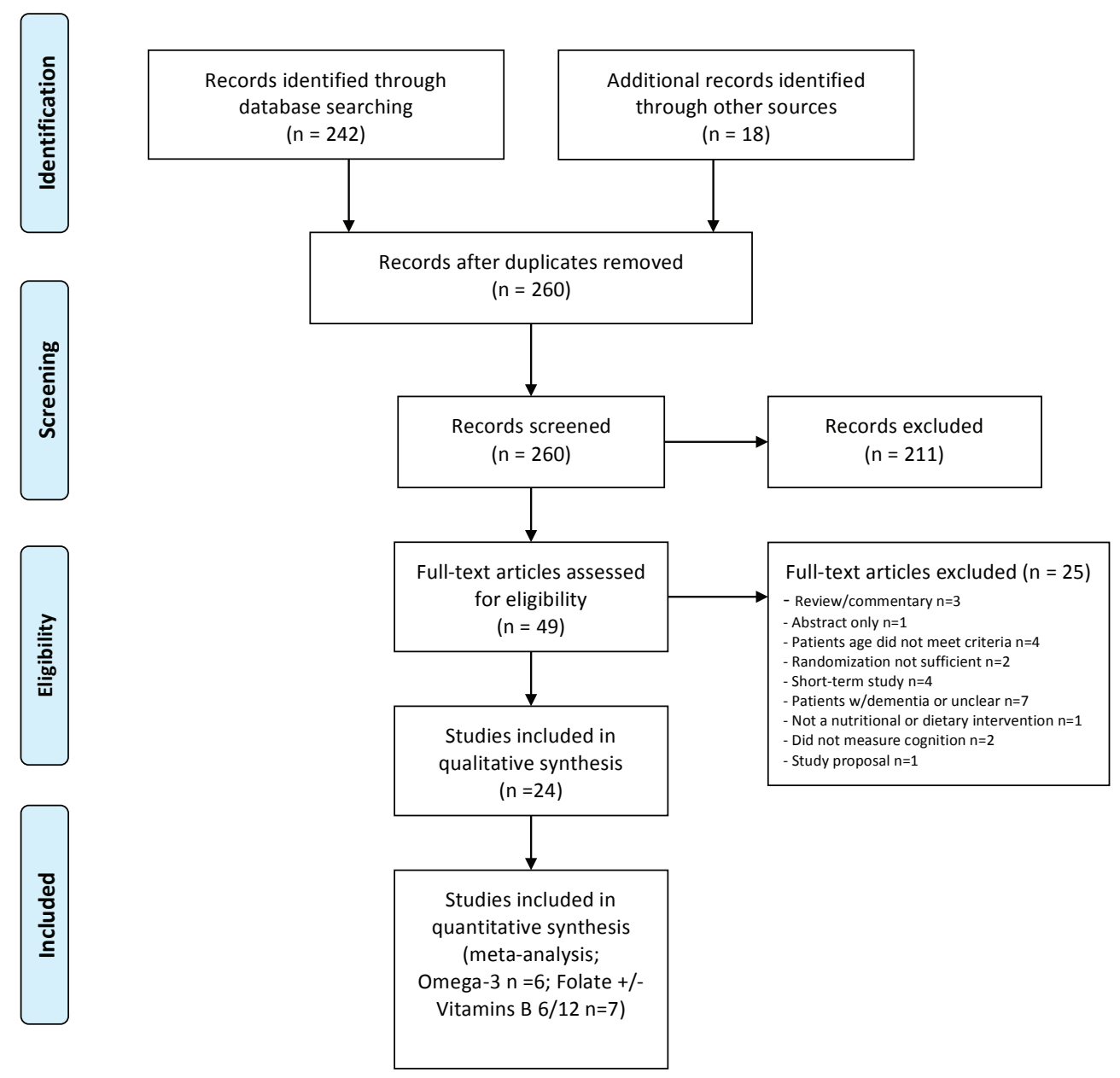

FIGURE 1. Literature search flow diagram

\section{Risk of Bias and Evidence of Publication Bias}

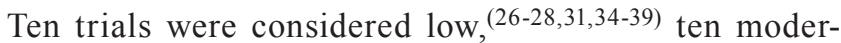
ate, ${ }^{(29,32,33,40-42,46-49)}$ and four high risk $^{(30,43-45)}$ of bias (Tables 1-4). Funnel plots for each meta-analysis were visually inspected and showed no evidence of publication bias.

\section{DISCUSSION}

This systematic review and meta-analysis presents data on recent RCTs of the cognitive impact of nutritional interventions in non-demented middle-aged and older adults. Our main finding is that there is no convincing evidence of benefit for any of the nutritional interventions included in this review. Meta-analyses of two nutritional interventions, omega-3 fatty acids, and select B vitamins (folate, B6 and/or B12) didn't demonstrate significant effects. The promising results of generally small single studies with moderate to high risk of bias reporting on other nutritional interventions will require confirmation.
In general, observational studies have been more positive than experimental ones. For example, though several observational studies $^{(50-53)}$ suggest that a high intake of omega-3 might lead to improve cognition, the RCTs examined showed no benefit ${ }^{(26,30,31)}$ or at most a modest one. ${ }^{(27-29)}$ Observational studies can lead to erroneous conclusions and must be interpreted cautiously. ${ }^{(54)}$ The risk of a confounding variable leading to the groups being compared (e.g., those following a particular diet versus those not) differing in their probability of the outcome of interest (e.g., developing cognitive problems) for reasons other than the intervention is a major limitation with them. This can occur if one is unaware of potential confounders, does not measure them, or does not measure them adequately. In many circumstances, to more firmly establish causality, a RCT is required.

Biologically plausible mechanisms are present for most of the nutritional interventions examined. Omega-3 fatty acids play a critical role in central nervous system development, structure, and function. ${ }^{(55)}$ Folate, vitamin B6, and/or vitamin B12 are considered essential for normal brain function as we 
FORBES: NUTRITION AND COGNITION

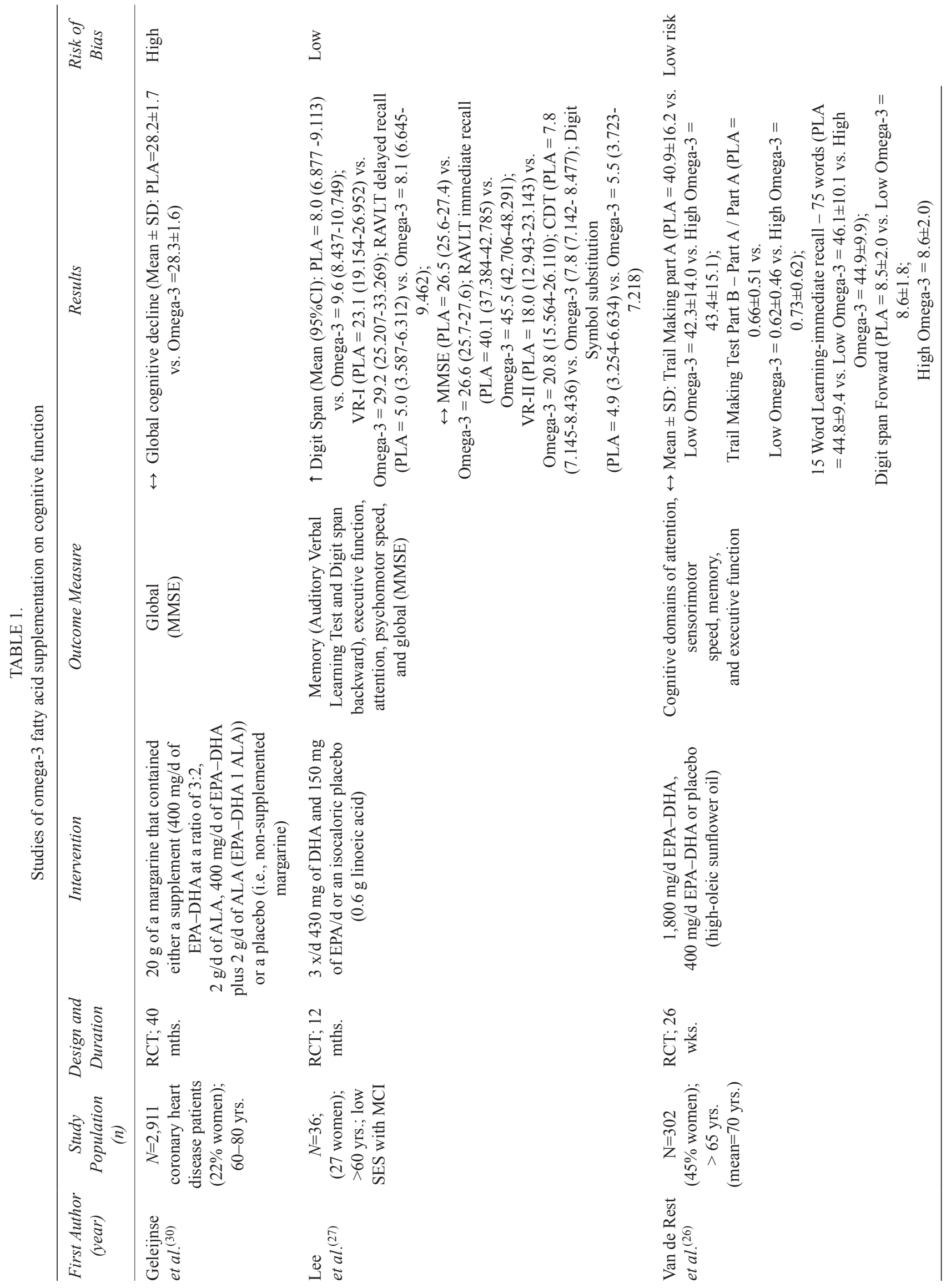

CANADIAN GERIATRICS JOURNAL, VOLUME 18, ISSUE 4, DECEMBER 2015 
FORBES: NUTRITION AND COGNITION

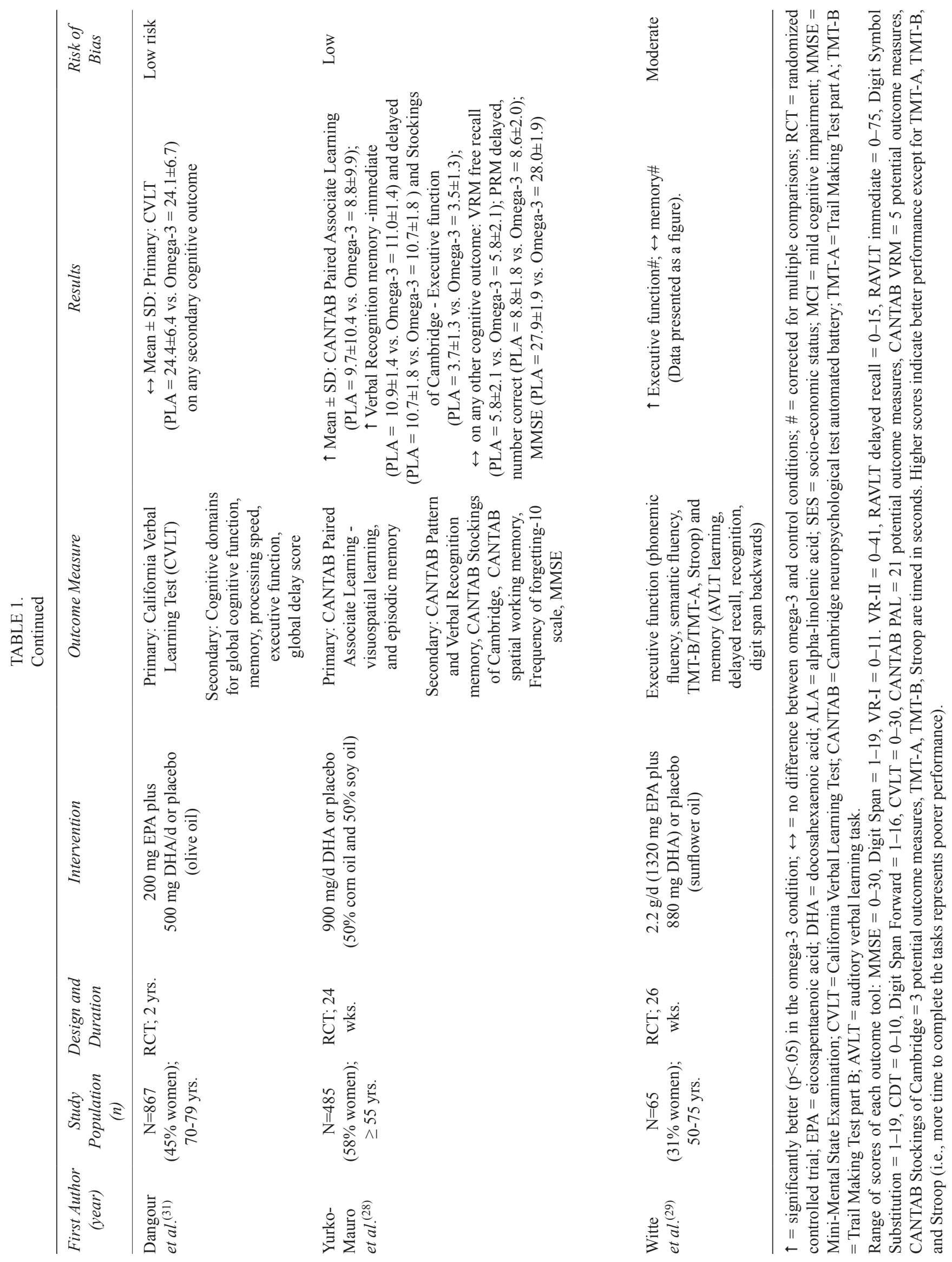


A

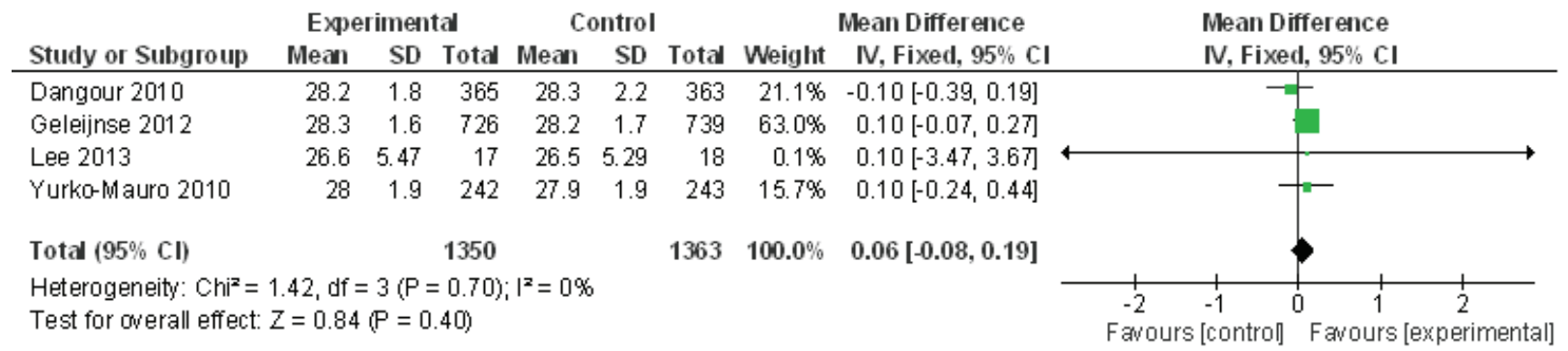

B

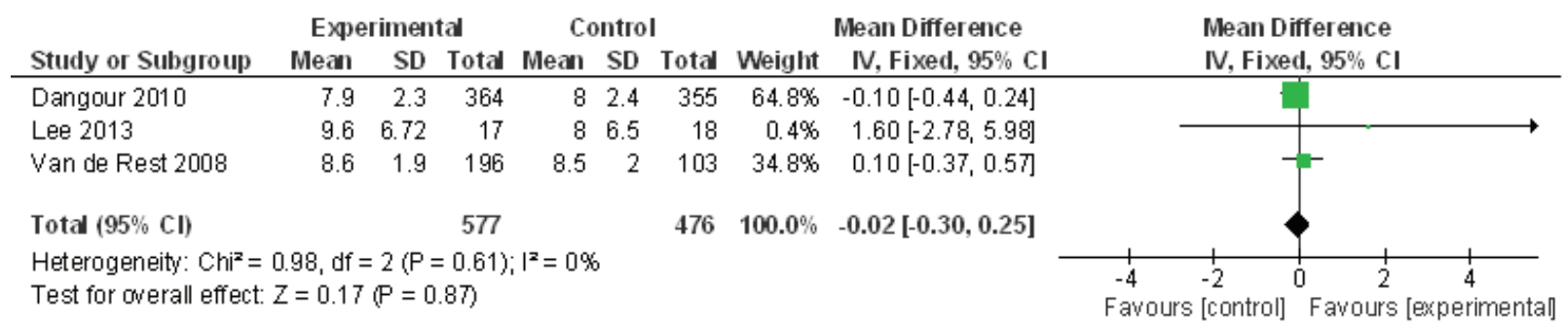

FIGURE 2. Meta-analyses of polyunsaturated omega-3 studies for the outcomes of (A) Mini-Mental State Examination (MMSE) score and (B) digit span forward

age $^{(56)}$ as a result of their effect on homocysteine metabo$\operatorname{lism}^{(56,57)}$ and other mechanisms. ${ }^{(58,59)}$ Vitamin E and several of the other nutrients examined are felt to have anti-oxidant effects. Long-term oxidative stress has been implicated in the pathogenesis of cognitive decline and dementia. ${ }^{(60)}$ Consumption of anti-oxidants, such as vitamin E, could potentially decrease free radical mediated damage in neuronal cells and reduce beta amyloid toxicity. ${ }^{(61)}$ An in vitro model of green tea extract was found to attenuate cell death induced by beta amyloid. ${ }^{(62)}$ Insulin resistance is associated with cognitive impairment, ${ }^{(63)}$ and chromium may improve insulin sensitivity. ${ }^{(64)}$ Determining, though, how much weight to give these purported mechanisms is difficult, cannot be done in isolation from other forms of evidence (e.g., clinical studies), and ultimately is often subjective. ${ }^{(65)}$

$B$ vitamins have attracted particular interest as a possible nutritional intervention. ${ }^{(56)}$ Folate acts as a donor of methyl groups in a reaction catalyzed by the enzyme methionine synthase to produce methylcobalamin, which is required for methylation of homocysteine to methionine. ${ }^{(56)} \mathrm{B}$-vitamin deficiency leads to an increase in blood concentrations of homocysteine. ${ }^{(66)}$ High intra-neuronal levels of homocysteine could disturb brain metabolism and cause cognitive impairment. ${ }^{(56)}$ Additionally, folate increases nitric oxide availability in the brain, ${ }^{(58)}$ and deficiency of this molecule impairs DNA repair in neurons and sensitizes neurons to oxidative damage and the toxicity of amyloid beta-peptide. ${ }^{(59)}$ A cohort study of 965 older adults demonstrated a lower incidence of Alzheimer's disease in the highest quartile of total dietary folate intake after controlling for other factors. ${ }^{(67)} \mathrm{We}$ identified seven $\mathrm{RCTs}$ investigating the influence of $\mathrm{B}$ vitamins on cognition
(Table 2). Our meta-analysis showed no significant effect of supplementation on MMSE scores. One study did show better cognitive performance with active therapy but only in women with low baseline dietary folate intake. ${ }^{(33)}$ Future RCTs should consider initial nutritional status, as benefits may be limited to those with relative deficiencies. ${ }^{(33)}$

Our findings are congruent with the previous systematic reviews. While Manders et al., ${ }^{(22)}$ in an examination of the available literature on the cognitive effects of nutritional supplements in older individuals concluded that their use might lead to improvements without causing any harm, the two more recent systematic reviews on this topic found little if any evidence of a beneficial effect. ${ }^{(23,24)}$

A number of systematic reviews have dealt with specific nutritional interventions. One examined population-based cohort studies of anti-oxidant nutrients and reported a possible effect on age-related cognitive decline though the available evidence was limited. ${ }^{(68)}$ Recent Cochrane systematic reviews concluded that both omega- $3^{(69)}$ and folate $( \pm \text { vitamin B12 })^{(70)}$ had no consistent beneficial effect on cognitive functioning in healthy older individuals.

Limitations of this review include the limited extent and quality of the available literature. Even when there are a number of studies dealing with the same nutritional intervention, the results do not necessarily show a consistent picture. While this may be due to differences in study population and/ or outcome measures, an issue requiring attention is the variability in the composition, dose, duration, and timing (during the participant's life span) of the intervention. For example, the ratio of omega- 6 to -3 may be an important consideration for omega-3 trials. ${ }^{(71)}$ There is increasing evidence that a 
FORBES: NUTRITION AND COGNITION

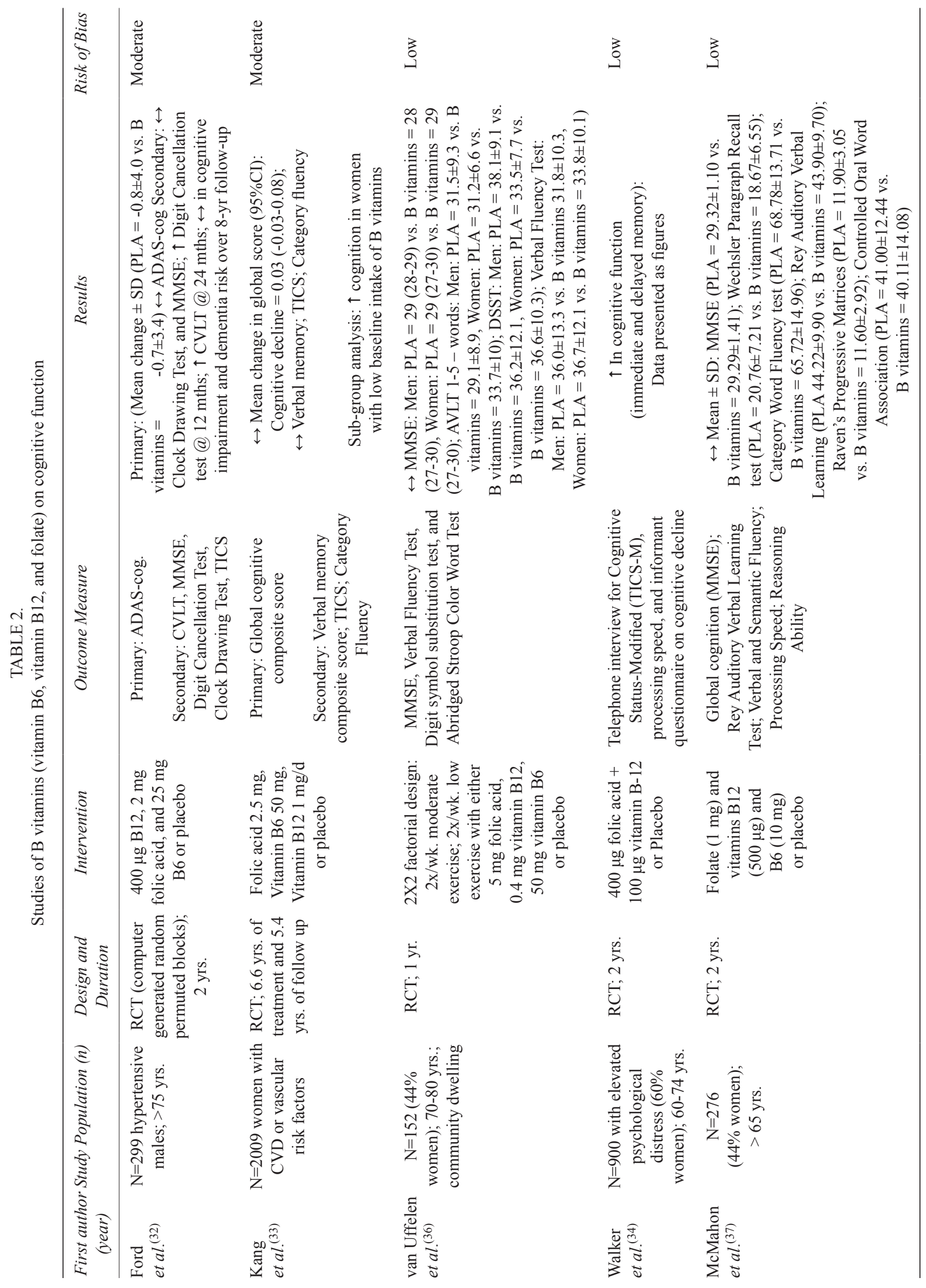

CANADIAN GERIATRICS JOURNAL, VOLUME 18, ISSUE 4, DECEMBER 2015 
FORBES: NUTRITION AND COGNITION
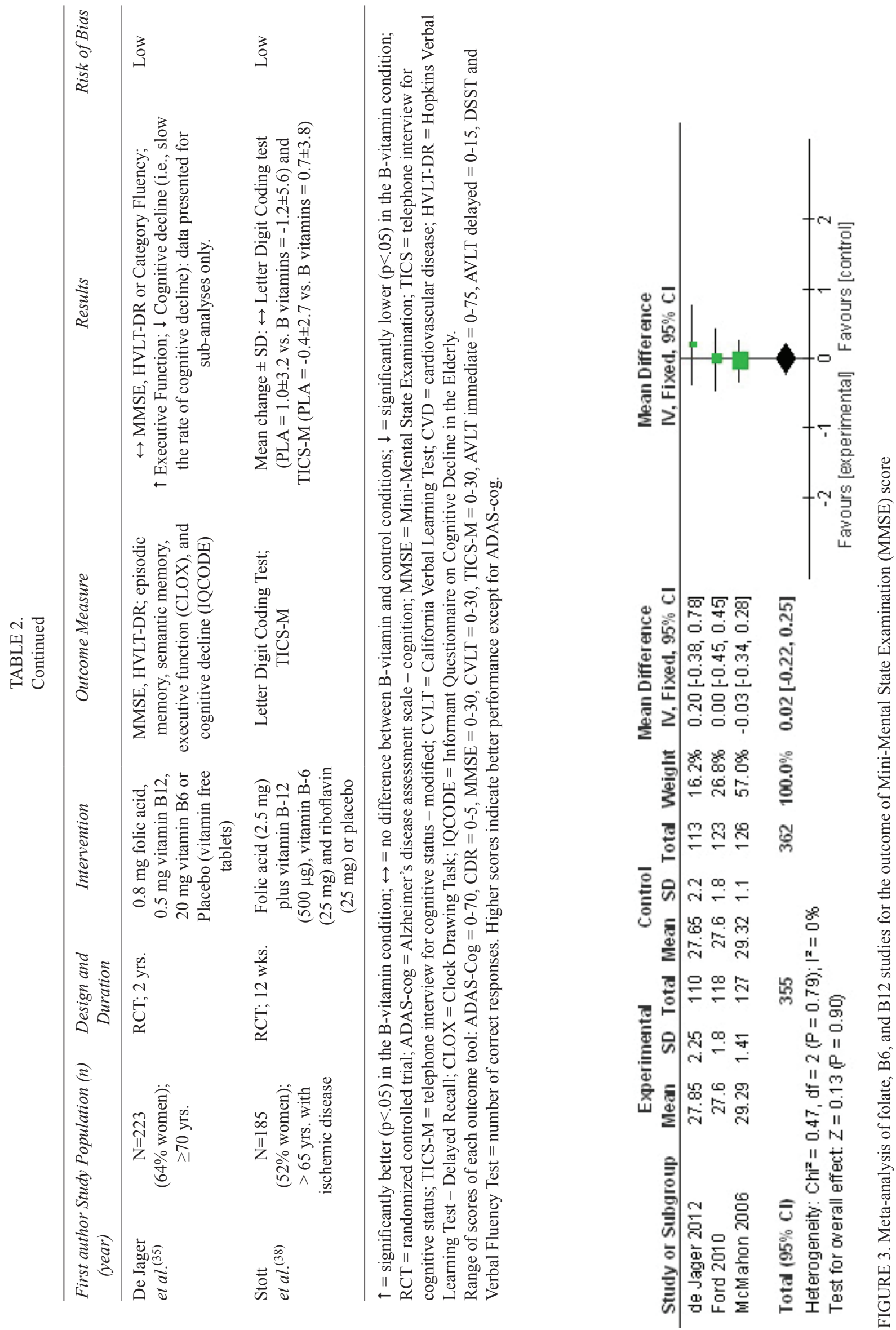
TABLE 3.

Studies of vitamin E supplementation on cognitive function

\begin{tabular}{|c|c|c|c|c|c|c|}
\hline $\begin{array}{l}\text { First author } \\
\text { (year) }\end{array}$ & $\begin{array}{c}\text { Study Population } \\
\text { (n) }\end{array}$ & $\begin{array}{c}\text { Design and } \\
\text { Duration }\end{array}$ & Intervention & Outcome Measure & Results & Risk of Bias \\
\hline $\begin{array}{l}\text { Kang } \\
\text { et al. }{ }^{(41)}\end{array}$ & $\begin{array}{l}\mathrm{N}=2824 \text { women; } \\
\quad>65 \text { yrs.; } \\
\geq 3 \text { coronary } \\
\text { risk factors }\end{array}$ & $\begin{array}{l}\mathrm{RCT} ; 5.4 \text { yrs. } \\
\text { follow up time }\end{array}$ & $\begin{array}{l}\text { Vitamin E } 402 \mathrm{mg} \\
\text { every other day }+ \\
500 \mathrm{mg} \text { of vitamin } \\
\mathrm{C} \text { daily and } 50 \mathrm{mg} \\
\text { of B-carotene every } \\
\text { other day or placebo }\end{array}$ & $\begin{array}{l}\text { Telephone interview } \\
\text { for Cognitive Status- } \\
\text { Modified (TICS-M) }\end{array}$ & $\begin{array}{c}\leftrightarrow \text { Rates of cognitive } \\
\text { change; data presented as } \\
\text { figures }\end{array}$ & Moderate \\
\hline $\begin{array}{l}\text { Kang } \\
\text { et al. }^{(40)}\end{array}$ & $\begin{aligned} \mathrm{N}= & 6377 \text { women; } \\
& >65 \text { yrs. }\end{aligned}$ & $\begin{array}{l}\text { RCT; } \\
\text { follow up at } \\
\sim 5.6 \text { yrs. and } \\
\text { at } \sim 9.6 \text { yrs. }\end{array}$ & $\begin{array}{l}\text { Vitamin E (600 IU) } \\
\text { or placebo }\end{array}$ & $\begin{array}{c}\text { Primary: } \\
\text { Global composite score } \\
\text { (TICS) } \\
\text { Secondary: } \\
\text { Verbal memory } \\
\text { (TICS \& East Boston } \\
\text { Memory Test) }\end{array}$ & $\begin{array}{c}\text { Mean } \pm \text { SE: } \leftrightarrow \text { Global } \\
\text { cognitive scores } \\
\text { (PLA }=0.02 \pm 0.01 \text { vs. } \\
\text { Vitamin } \mathrm{E}=0.02 \pm 0.01 \text { ) } \\
\leftrightarrow \text { verbal memory } \\
\text { at both follow-ups }\end{array}$ & Moderate \\
\hline $\begin{array}{l}\text { Petersen } \\
\text { et al. }\end{array}$ & $\begin{array}{l}\mathrm{N}=769 \\
(46 \% \text { women }) \\
72.9 \pm 7.3 \text { yrs.; } \\
\text { Amnestic MCI }\end{array}$ & RCT; 3 yrs. & $\begin{array}{l}\text { Vitamin E (2000 IU) } \\
\text { or Donepezil (10 mg) } \\
\text { or placebo }\end{array}$ & $\begin{array}{l}\text { Primary: Possible or } \\
\text { probably AD } \\
\text { Secondary: MMSE; } \\
\text { ADAS-Cog; global CDR; } \\
\text { CDR sum of boxes; Global } \\
\text { Deterioration Scale; } \\
\text { New York University } \\
\text { paragraph-recall test; the } \\
\text { symbol digit modalities } \\
\text { test; category-fluency test; } \\
\text { a number cancellation } \\
\text { test; Boston Naming Test; } \\
\text { Digits-backward test; clock } \\
\text { drawing test; maze-tracing } \\
\text { task. }\end{array}$ & $\begin{array}{c}\leftrightarrow \text { Probability of } \\
\text { progression from MCI } \\
\text { to } \mathrm{AD} \text { (hazard ratio, } \\
1.02 ; 95 \% \mathrm{CI}, \\
0.74-1.41) ; \leftrightarrow \text { in any } \\
\text { of the secondary } \\
\text { outcome variables } \\
\text { after } 3 \text { yrs. }\end{array}$ & Low \\
\hline
\end{tabular}

$\leftrightarrow=$ no difference between vitamin E and control conditions; RCT = randomized controlled trial; ADAS-cog = Alzheimer's disease assessment scale - cognition; MMSE = Mini-Mental State Examination; TICS = telephone interview for cognitive status; TICS-M = telephone interview for cognitive status - modified; $\mathrm{AD}=$ Alzheimer's disease; $\mathrm{CDR}=$ clinical dementia rating.

lifetime of accumulated exposures are predictive of cognitive function in late-life. ${ }^{(4)}$ An intervention limited to later in the person's life may be beyond the critical period when it may be beneficial. More thought about the influence of the specific characteristics of the intervention is needed during the planning stage of these studies. Also relatively neglected is assessing the initial nutritional status of participants. Benefits may be limited to those with relative deficiencies. ${ }^{(72)}$ In one of the B vitamin studies reviewed, ${ }^{(33)}$ better cognitive performance was seen with active therapy but only in women with low baseline dietary folate intake. Another issue might be the relative insensitivity of the outcome measures utilized (e.g., MMSE).

Recent research suggests that considering the person's "whole" diet may be needed to better understand the nutrient-cognition link. ${ }^{(73)}$ Supplements cannot replicate the complexity of natural food and provide all its potential benefits. Conducting rigorous long-term studies of the effect of diet on cognition will be a difficult challenge. ${ }^{(74)}$ One of the dietary approaches that might be considered is caloric restriction. This may have a beneficial impact by increasing insulin sensitivity. ${ }^{(75)}$ One of our included studies examined a dietary approach developed for hypertension. ${ }^{(48)}$ Risk factors for Alzheimer's disease and vascular dementia overlap with those for heart disease. ${ }^{(4,76)}$ A recent meta-analysis of observational studies found high adherence to a Mediterranean diet was associated with a lower risk of developing cognitive impairment, ${ }^{(77,78)}$ but no interventional studies that met our inclusion criteria were found. While the PREDIMED-Navarra investigators found small but statistically significant differences in favour of those assigned to a Mediterranean diet supplemented with 
FORBES: NUTRITION AND COGNITION

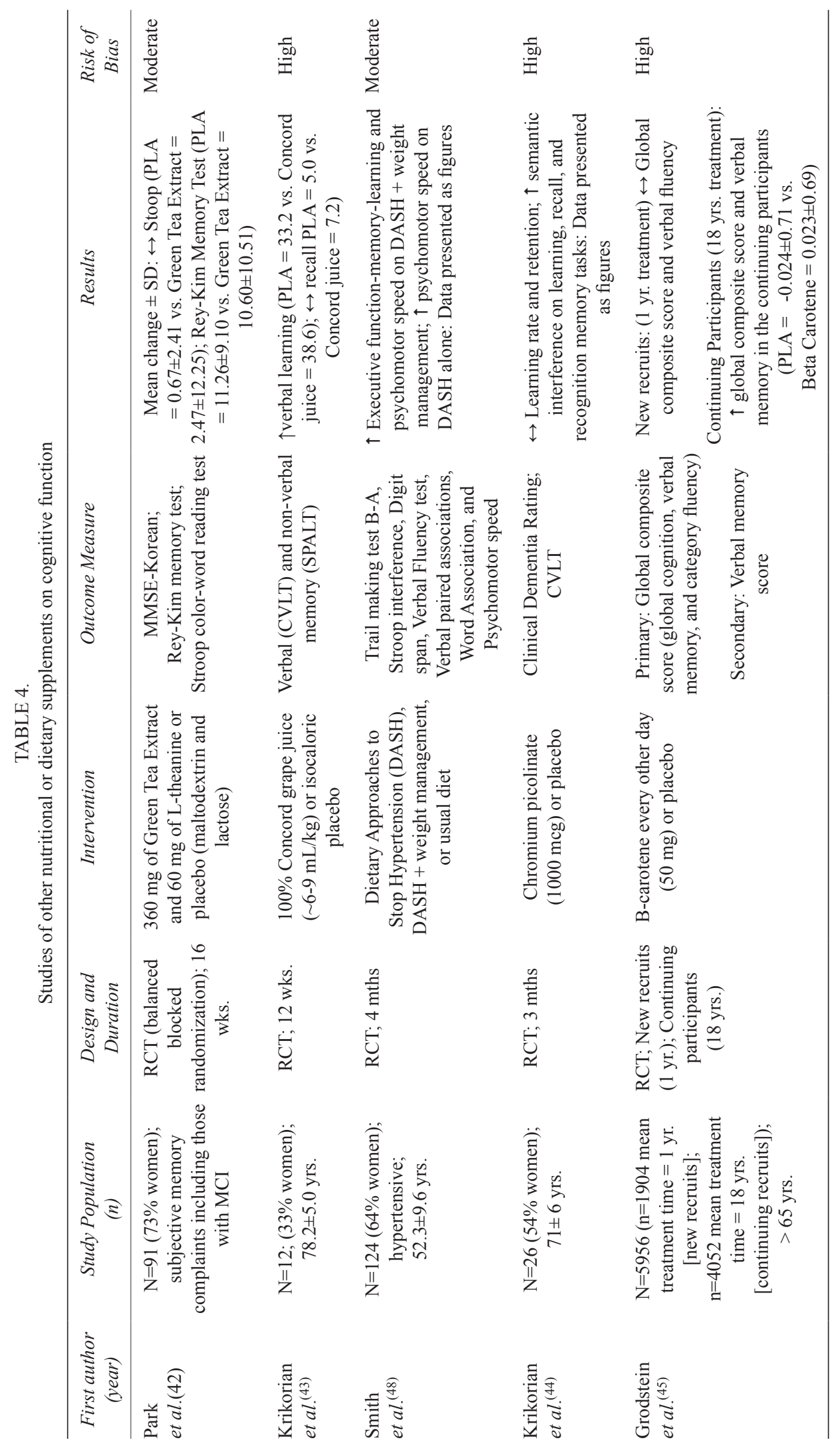

CANADIAN GERIATRICS JOURNAL, VOLUME 18, ISSUE 4, DECEMBER 2015 
FORBES: NUTRITION AND COGNITION

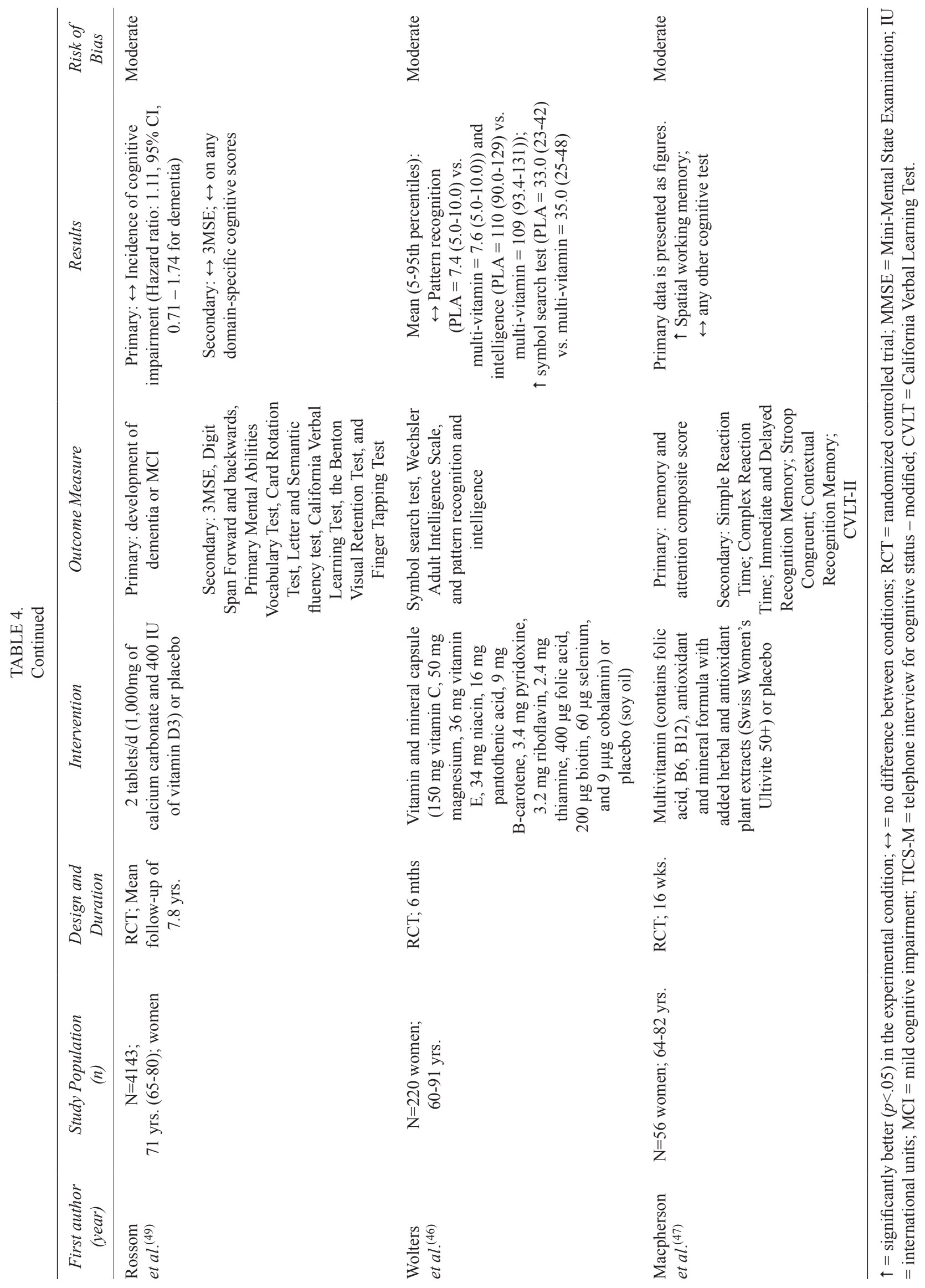


extra-virgin olive oil on several cognitive measures after an average of 6.5 years, ${ }^{(79,80)}$ cognitive testing was not done at baseline. As a result, change in cognition in response to the intervention could not be evaluated. As well, the testing was done only on sub-groups of participants randomized at one PREDIMED recruitment site. Other components of a healthy lifestyle, such as exercise, may be important modulators of the relationship between dietary intake and cognition. ${ }^{(81)}$ Their influence should also be considered in future research.

Much of the research demonstrating a potential link between nutrition and cognition is observational, done on animals, or in vitro and may not be relevant to clinical practice. Our meta-analyses demonstrated no overall effect of omega-3 fatty acids or select B-vitamin supplementation on cognition. Green tea extract, chromium, anti-oxidants, and the DASH (Dietary Approaches to Stop Hypertension) diet deserve further exploration but cannot be recommended at this juncture. Future research should utilize rigorous study methods that incorporate baseline dietary assessments, consider potential modulation by other components of a healthy lifestyle, and use common and robust outcome measures.

\section{ACKNOWLEDGEMENTS}

The authors gratefully acknowledge the support received from the Brenda Stafford Centre on Aging (SCF), the Brenda Strafford Foundation Chair in Geriatric Medicine (DBH), the Brenda Strafford Foundation Chair in Alzheimer Research (MJP; SCF) of the University of Calgary, and the Canadian Institutes of Health Research (Funding Reference Number MOP-93717; MJ Poulin PI). The funders played no role in the design and conduct of the study, analysis of the data, or the drafting of this submission.

\section{CONFLICT OF INTEREST DISCLOSURES}

The authors have no competing interests to declare.

\section{REFERENCES}

1. Prince M, Guerchet, M, Prina, M. Alzheimer's Disease International. Policy brief for heads of government: the global impact of dementia 2013-2050. Alzheimer's Disease International. 2013. Available at: https://www.alz.co.uk/research/Global ImpactDementia2013.pdf

2. Hurd MD, Martorell P, Delavande A, et al. Monetary costs of dementia in the United States. New Eng JMed. 2013;368(14):1326-34.

3. International WHO. aAD. Dementia: a public health priority. 2012. Available at: http://www.who.int/mental_health/ publications/dementia report_2012/en/

4. Yaffe K, VittinghoffE, Pletcher MJ, et al. Early adult to mid-life cardiovascular risk factors and cognitive function. Circulation. 2014; 129:1548-50.

5. Larson EB, Yaffe K, Langa KM. New insights into the dementia epidemic. New Eng J Med. 2013;369(24):2275-77.
6. Schrijvers EM, Verhaaren BF, Koudstaal PJ, et al. Is dementia incidence declining? Trends in dementia incidence since 1990 in the Rotterdam study. Neurology. 2012;78(19):1456-63.

7. Qiu C, von Strauss E, Bäckman L, et al. Twenty-year changes in dementia occurrence suggest decreasing incidence in central Stockholm, Sweden. Neurology. 2013;80(20):1888-94.

8. Matthews FE, Arthur A, Barnes LE, et al. A two-decade comparison of prevalence of dementia in individuals aged 65 years and older from three geographical areas of England: results of the Cognitive Function and Ageing Study I and II. Lancet. 2013;382(9902):1405-12.

9. Daviglus ML, Bell CC, Berrettini W, et al. National Institutes of Health State-of-the-Science Conference statement: preventing Alzheimer disease and cognitive decline. Ann Intern Med. 2010;153(3):176-81.

10. Brookmeyer R, Gray S. Methods for projecting the incidence and prevalence of chronic diseases in aging populations: application to Alzheimer's disease. Stat Med. 2000;19(11-12):1481-93.

11. Morris MC, Evans DA, Bienias JL, et al. Dietary fat intake and 6-year cognitive change in an older biracial community population. Neurology. 2004;62(9):1573-79.

12. Kalmijn S, van Boxtel MP, Ocke M, et al. Dietary intake of fatty acids and fish in relation to cognitive performance at middle age. Neurology. 2004;62(2):275-80.

13. Haan MN, Miller JW, Aiello AE, et al. Homocysteine, B vitamins, and the incidence of dementia and cognitive impairment: results from the Sacramento Area Latino Study on Aging. Am J Clin Nutr. 2007;85(2):511-17.

14. Engelhart MJ, Geerlings MI, Ruitenberg A, et al. Dietary intake of antioxidants and risk of Alzheimer disease. JAMA. 2002;287(24):3223-29.

15. Devore EE, Grodstein F, van Rooij FJ, et al. Dietary antioxidants and long-term risk of dementia. Arch Neurol. 2010;67(7):819-25.

16. Slinin Y, Paudel ML, Taylor BC, et al. 25-Hydroxyvitamin D levels and cognitive performance and decline in elderly men. Neurology. 2010;74(1):33-41.

17. Gillette-Guyonnet S, Secher M, Vellas B. Nutrition and neurodegeneration: epidemiological evidence and challenges for future research. Br J Clin Pharmacol. 2013;75(3):738-55.

18. Gillette Guyonnet S, Abellan Van Kan G, Andrieu S, et al. IANA task force on nutrition and cognitive decline with aging. J Nutr Health Aging. 2007;11(2):132-52.

19. Swaminathan A, Jicha GA. Nutrition and prevention of Alzheimer's dementia. Front Aging Neurosci. 2014;6:282.

20. Higgins JPT, Green S, editors. Cochrane handbook for systematic reviews of interventions 5.1.0 (updated March 2011): The Cochrane Collaboration, 2011. Available from: www. cochrane-handbook.org

21. Moher D, Liberati A, Tetzlaff J, et al. Preferred reporting items for systematic reviews and meta-analyses: the PRISMA statement. J Clin Epidemiol. 2009;62(10):1006-12.

22. Manders M, de Groot LC, van Staveren WA, et al. Effectiveness of nutritional supplements on cognitive functioning in elderly persons: a systematic review. J Gerontol A Biol Sci Med Sci. 2004;59(10):M1041-49. 
23. Jia X, McNeill G, Avenell A. Does taking vitamin, mineral and fatty acid supplements prevent cognitive decline? A systematic review of randomized controlled trials. J Hum Nutr Diet. 2008;21(4):317-36.

24. Williams JW, Plassman BL, Burke J, et al. Preventing Alzheimer's disease and cognitive decline. Rockville (MD): Agency for Healthcare Research and Quality (US). Evidence report/technology assessment, No. 193. 2010. 727p. Available from: http://www.ncbi.nlm.nih.gov/books/NBK47456/.

25. The Consumer Food Trends Series. 2014. Available from: http://www.worldcat.org/title/consumer-food-trends-definingopportunities-for-albertas-agri-food-industry/oclc/802069366.

26. van de Rest O, Geleijnse JM, Kok FJ, et al. Effect of fish oil on cognitive performance in older subjects: a randomized, controlled trial. Neurology. 2008;71(6):430-38.

27. Lee LK, Shahar S, Chin AV, et al. Docosahexaenoic acid-concentrated fish oil supplementation in subjects with mild cognitive impairment (MCI): a 12-month randomised, double-blind, placebo-controlled trial. Psychopharmacology. 2013;225(3):605-12.

28. Yurko-Mauro K, McCarthy D, Rom D, et al. Beneficial effects of docosahexaenoic acid on cognition in age-related cognitive decline. Alzheimers Dement. 2010;6(6):456-64.

29. Witte AV, Kerti L, Hermannstädter HM, et al. Long-Chain Omega-3 Fatty Acids Improve Brain Function and Structure in Older Adults. Cereb Cortex. 2014;24(11):3059-68.

30. Geleijnse JM, Giltay EJ, Kromhout D. Effects of n-3 fatty acids on cognitive decline: a randomized, double-blind, placebo-controlled trial in stable myocardial infarction patients. Alzheimers Dement. 2012;8(4):278-87.

31. Dangour AD, Allen E, Elbourne D, et al. Effect of 2-y n-3 longchain polyunsaturated fatty acid supplementation on cognitive function in older people: a randomized, double-blind, controlled trial. Am J Clin Nutr. 2010;91(6):1725-32.

32. Ford AH, Flicker L, Alfonso H, et al. Vitamins B(12), $\mathrm{B}(6)$, and folic acid for cognition in older men. Neurology. 2010;75(17):1540-47.

33. Kang JH, Cook N, Manson J, et al. A trial of B vitamins and cognitive function among women at high risk of cardiovascular disease. Am J Clin Nutr. 2008;88(6):1602-10.

34. Walker JG, Batterham PJ, Mackinnon AJ, et al. Oral folic acid and vitamin B-12 supplementation to prevent cognitive decline in community-dwelling older adults with depressive symptoms - the Beyond Ageing Project: a randomized controlled trial. Am J Clin Nutr. 2012;95(1):194-203.

35. de Jager CA, Oulhaj A, Jacoby R, et al. Cognitive and clinical outcomes of homocysteine-lowering B-vitamin treatment in mild cognitive impairment: a randomized controlled trial. Int J Geriatr Psychiatry. 2012;27(6):592-600.

36. van Uffelen JG, Chinapaw MJ, van Mechelen W, et al. Walking or vitamin $\mathrm{B}$ for cognition in older adults with mild cognitive impairment? A randomised controlled trial. Br J Sports Med. 2008;42(5):344-51.

37. McMahon JA, Green TJ, Skeaff CM, et al. A controlled trial of homocysteine lowering and cognitive performance. $N$ Engl J Med. 2006;354(26):2764-72.
38. Stott DJ, MacIntosh G, Lowe GD, et al. Randomized controlled trial of homocysteine-lowering vitamin treatment in elderly patients with vascular disease. Am J Clin Nutr. 2005;82(6):1320-26.

39. Petersen RC, Thomas RG, Grundman M, et al. Vitamin E and donepezil for the treatment of mild cognitive impairment. $N$ Engl J Med. 2005;352(23):2379-88.

40. Kang JH, Cook N, Manson J, et al. A randomized trial of vitamin E supplementation and cognitive function in women. Arch Intern Med. 2006;166(22):2462-68.

41. Kang JH, Cook NR, Manson JE, et al. Vitamin E, vitamin C, beta carotene, and cognitive function among women with or at risk of cardiovascular disease: The Women's Antioxidant and Cardiovascular Study. Circulation. 2009;119(21):2772-80.

42. Park SK, Jung IC, Lee WK, et al. A combination of green tea extract and 1-theanine improves memory and attention in subjects with mild cognitive impairment: a double-blind placebocontrolled study. J Med Food. 2011;14(4):334-43.

43. Krikorian R, Nash TA, Shidler MD, et al. Concord grape juice supplementation improves memory function in older adults with mild cognitive impairment. Br J Nutr. 2010;103(5):730-34.

44. Krikorian R, Eliassen JC, Boespflug EL, et al. Improved cognitive-cerebral function in older adults with chromium supplementation. Nutr Neurosci. 2010;13(3):116-22.

45. Grodstein F, Kang JH, Glynn RJ, et al. A randomized trial of beta carotene supplementation and cognitive function in men: the Physicians' Health Study II. Arch Intern Med. 2007;167(20):2184-90.

46. Wolters M, Hickstein M, Flintermann A, et al. Cognitive performance in relation to vitamin status in healthy elderly German women - the effect of 6-month multivitamin supplementation. Prev Med. 2005;41(1):253-59.

47. Macpherson H, Ellis KA, Sali A, et al. Memory improvements in elderly women following 16 weeks treatment with a combined multivitamin, mineral and herbal supplement: A randomized controlled trial. Psychopharmacology. 2012;220(2):351-65.

48. Smith PJ, Blumenthal JA, Babyak MA, et al. Effects of the dietary approaches to stop hypertension diet, exercise, and caloric restriction on neurocognition in overweight adults with high blood pressure. Hypertension. 2010;55(6):1331-38.

49. Rossom RC, Espeland MA, Manson JE, et al. Calcium and vitamin D supplementation and cognitive impairment in the women's health initiative. J Am Geriatr Soc. 2012;60(12):2197-205.

50. Fotuhi M, Mohassel P, Yaffe K. Fish consumption, long-chain omega-3 fatty acids and risk of cognitive decline or Alzheimer disease: a complex association. Nat Clin Pract Neurol. 2009;5(3):140-52.

51. Hooijmans CR, Pasker-de Jong PC, de Vries RB, et al. The effects of long-term omega-3 fatty acid supplementation on cognition and Alzheimer's pathology in animal models of Alzheimer's disease: a systematic review and meta-analysis. $J$ Alzheimers Dis. 2012;28(1):191-209.

52. Cederholm T, Palmblad J. Are omega-3 fatty acids options for prevention and treatment of cognitive decline and dementia? Curr Opin Clin Nutr Metab Care. 2010;13(2):150-55. 
53. Muldoon MF, Ryan CM, Sheu L, et al. Serum phospholipid docosahexaenonic acid is associated with cognitive functioning during middle adulthood. J. Nutr. 2010;140(4):848-53.

54. Spector R, Vesell ES. Which studies of therapy merit credence? Vitamin E and estrogen therapy as cautionary examples. J Clin Pharmacol. 2002;42(9):955-62.

55. Gomez-Pinilla F, Kostenkova K. The influence of diet and physical activity on brain repair and neurosurgical outcome. Surg Neurol. 2008;70(4):333-36.

56. Garcia A, Zanibbi K. Homocysteine and cognitive function in elderly people. CMAJ. 2004;171(8):897-904.

57. Luchsinger JA, Tang MX, Miller J, et al. Relation of plasma homocysteine to plasma amyloid beta levels. Neurochem Res. 2007;32(4-5):775-81.

58. Stroes ES, van Faassen EE, Yo M, et al. Folic acid reverts dysfunction of endothelial nitric oxide synthase. Circ Res. 2000;86(11):1129-34.

59. Kruman II, Kumaravel TS, Lohani A, et al. Folic acid deficiency and homocysteine impair DNA repair in hippocampal neurons and sensitize them to amyloid toxicity in experimental models of Alzheimer's disease. J Neurosci. 2002;22(5):1752-62.

60. Meydani M, Hernandez-Rodriguez J, Youdim MBH, et al. Antioxidants and cognitive function. Nutr Rev. 2001;59(82):S75-82.

61. Butterfield DA, Castegna A, Lauderback CM, et al. Evidence that amyloid beta-peptide-induced lipid peroxidation and its sequelae in Alzheimer's disease brain contribute to neuronal death. Neurobiol Aging. 2002;23(5):655-64.

62. Lee SY, Lee JW, Lee H, et al. Inhibitory effect of green tea extract on beta-amyloid-induced PC12 cell death by inhibition of the activation of NF-kappaB and ERK/p38 MAP kinase pathway through antioxidant mechanisms. Brain Res Mol Brain Res. 2005; 140(1-2):45-54.

63. Frölich L, Blum-Degen D, Bernstein HG, et al. Brain insulin and insulin receptors in aging and sporadic Alzheimer's disease. J Neural Transm. 1998;105(4-5):423-38.

64. Hua Y, Clark S, Ren J, et al. Molecular mechanisms of chromium in alleviating insulin resistance. J Nutr Biochem. 2012;23(4):313-19.

65. Potischman N, Weed DL. Causal criteria in nutritional epidemiology. Am J Clin Nutr. 1999;69(6):1309S-14S.

66. Lindenbaum J, Rosenberg IH, Wilson PW, et al. Prevalence of cobalamin deficiency in the Framingham elderly population. Am J Clin Nutr. 1994;60(1):2-11.

67. Luchsinger JA, Tang MX, Miller J, et al. Relation of higher folate intake to lower risk of Alzheimer disease in the elderly. Arch Neurol. 2007;64(1):86-92..

68. Rafnsson SB, Dilis V, Trichopoulou A. Antioxidant nutrients and age-related cognitive decline: a systematic review of population-based cohort studies. Eur J Nutr. 2013;52(6):1553-67.
69. Sydenham E, Dangour AD, Lim WS. Omega 3 fatty acid for the prevention of cognitive decline and dementia. The Cochrane database of systematic reviews. 2012;6:CD005379.

70. Malouf R, Grimley Evans J. Folic acid with or without vitamin B12 for the prevention and treatment of healthy elderly and demented people. The Cochrane database of systematic reviews. 2008(4):CD004514.

71. Loef $M$, Walach $H$. The omega-6/omega-3 ratio and dementia or cognitive decline: a systematic review on human studies and biological evidence. J Nutr Gerontol Geriatr. 2013;32(1):1-23.

72. Galan P, Briançon S, Favier A, et al. Antioxidant status and risk of cancer in the SU.VI.MAX study: is the effect of supplementation dependent on baseline levels? Br J Nutr. 2005;94(1):125-32.

73. Cheung BH, Ho IC, Chan RS, et al. Current evidence on dietary pattern and cognitive function. Adv Food Nutr Res. 2014;71:137-63.

74. Katz DL, Meller S. Can we say what diet is best for health? Annu Rev Public Health. 2014;35:83-103.

75. Gillette-Guyonnet S, Vellas B. Caloric restriction and brain function. Curr Opin Clin Nutr Metab Care. 2008 Nov;11(6):686-92.

76. Sacco RL. Achieving ideal cardiovascular and brain health: opportunity amid crisis: Presidential Address at the American Heart Association 2010 Scientific Sessions. Circulation. 2011;123(22):2653-57.

77. Psaltopoulou T, Sergentanis TN, Panagiotakos DB, et al. Mediterranean diet, stroke, cognitive impairment, and depression: A meta-analysis. Ann Neurol. 2013;74(4):580-91.

78. Singh B, Parsaik AK, Mielke MM, et al. Association of mediterranean diet with mild cognitive impairment and Alzheimer's disease: a systematic review and meta-analysis. J Alzheimers Dis. 2014;39(2):271-82.

79. Martinez-Lapiscina EH, Clavero P, Toledo E, et al. Virgin olive oil supplementation and long-term cognition: the PREDIMED-NAVARRA randomized, trial. $J$ Nutr Health Aging. 2013;17(6):544-52.

80. Martinez-Lapiscina EH, Clavero P, Toledo E, et al. Mediterranean diet improves cognition: the PREDIMED-NAVARRA randomised trial. J Neurol Neurosurg Psychiatry. 2013;84(12):1318-25.

81. Middleton LE, Kirkland SA, Maxwell CJ, et al. Exercise: a potential contributing factor to the relationship between folate and dementia. J Am Geriatr Soc. 2007;55(7):1095-98.

Correspondence to: David B. Hogan, MD, HSC-3330 Hospital Dr. NW, Calgary, AB T2N 4N1, Canada

E-mail: dhogan@ucalgary.ca 